\title{
STUDY OF LEFT VENTRICULAR DYSFUNCTION IN NORMOTENSIVE TYPE 2 DIABETIC PATIENTS
}

\author{
Pradeep Nigam¹, Suraj Kathuria², Manoj Indurkar ${ }^{3}$
}

${ }^{1}$ Associate Professor, Department of Medicine, Shyam Shah Medical College and Associated SGM and GM Hospital, Rewa, Madhya Pradesh.

2Final Year Postgraduate Student, Department of Medicine, Shyam Shah Medical College and Associated SGM and GM Hospital, Rewa, Madhya Pradesh.

3Professor and HOD, Department of Medicine, Shyam Shah Medical College and Associated SGM and GM Hospital, Rewa, Madhya Pradesh.

ABSTRACT
BACKGROUND
Diabetes mellitus (DM) is known to affect cardiovascular system adversely. Various studies reported left ventricular dysfunction
(LVD) as an early sign of cardiac involvement in asymptomatic patients with type 2 DM, diagnosed using Colour Doppler
echocardiography. With this background, the study was conducted with an aim to study the prevalence of left ventricular
dysfunction in normotensive asymptomatic type-2 DM patients.

\section{MATERIALS AND METHODS}

The descriptive comparative study was carried out among the type 2 DM patients. 100 patients of diabetes mellitus with age $>35$ years were included in the study. The patients were taken from OPD and indoor wards of medicine department and patients without the history of hypertension, heart diseases and renal dysfunction were recruited on a convenient basis. Demographic data such as age, sex, history, duration, treatment of DM, investigations like fasting and postprandial blood sugar levels, serum creatinine, fasting lipid profile, HbA1c and also ECG, 2D echocardiography were carried out. Data were entered in MS Excel spread sheet and analysed with the help of SPSS software packages and Statistical analysis was done by using percentages, mean values, standard deviation, standard error, $\mathrm{x}^{2}$ test (Chi-square test) (with Yates correction) and t-test (unpaired).

\section{RESULTS}

$16(16 \%)$ patients had significantly decreased ejection fraction of $<50 \%$ out of $100,82(82 \%)$ patients had A/E ratio of $>1$ among 100 patients. A strong association of LVD with severity of Diabetes HbA1c ( $p<0.001)$ was observed, but there was no correlation with duration of Diabetes.

\section{CONCLUSION}

Uncontrolled diabetes with high level of HbA1c were found to have a strong association with LVD. It is recommended that all patients with long-term and uncontrolled type 2 DM should be screened for LVD.

\section{KEYWORDS}

LVD, Duration of Diabetes, HbA1c, Diabetic Cardiomyopathy.

HOW TO CITE THIS ARTICLE: Nigam P, Kathuria S, Indurkar M. Study of left ventricular dysfunction in normotensive type 2 diabetic patients. J. Evolution Med. Dent. Sci. 2018;7(03):324-327, DOI: 10.14260/jemds/2018/72

\section{BACKGROUND \\ Diabetes mellitus is a chronic multisystem disorder. According to World Health Organisation (WHO), the term diabetes mellitus describes a metabolic disorder of multiple aetiology characterised by chronic hyperglycaemia with disturbances of carbohydrate, fat and protein metabolism resulting from defects in insulin secretion, insulin action or both. Globally, an estimated 422 million adults are living with diabetes mellitus, according to the latest 2016 data from the World Health Organisation (WHO). Diabetes prevalence is increasing rapidly; previous 2013 estimates from the International Diabetes Federation put the number at 381 million people having diabetes.}

'Financial or Other Competing Interest': None.

Submission 24-11-2017, Peer Review 26-12-2017,

Acceptance 04-01-2018, Published 13-01-2018.

Corresponding Author:

Dr. Pradeep Nigam,

E-13, Old Doctors Colony,

Shyam Shah Medical College,

Rewa, Madhya Pradesh.

E-mail: dnigamdrp@yahoo.co.in

DOI: $10.14260 /$ jemds $/ 2018 / 72$

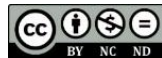

The number is projected to almost double by 2030. Type

2 diabetes makes up about $85 \%-90 \%$ of all cases. Increases in the overall diabetes prevalence rates largely reflect an increase in risk factors for type 2, notably greater longevity and being overweight or obese. The increase in incidence in developing countries follows the trend of urbanisation and lifestyle changes including increasingly sedentary lifestyles, less physically demanding work and the global nutrition transition, marked by increased intake of foods that are high energy-dense, but nutrient-poor (often high in sugar and saturated fats, sometimes referred to as the Western pattern diet).

Diabetes mellitus is independent risk factor for cardiovascular diseases (CVD). Cardiovascular diseases is the leading cause of diabetes-related death, responsible for up to three-fourths of all diabetic mortality. The factors which contribute to the increased incidence of cardiovascular diseases in diabetes mellitus is accelerated atherosclerosis, macrovascular complications, microvascular disease and cardiomyopathy. This pathophysiological phenomenon , directly or indirectly causes myocardial dysfunction, which is common and important determinant of cardiovascular morbidity. 


\section{MATERIALS AND METHODS}

The present study entitled "Study of Left Ventricular Dysfunction in Normotensive type-2 diabetic patients by 2D echocardiography" was carried out in Department of Medicine SGMH and associate Shyam Shah Medical College, Rewa (MP) from July 2016 to June 2017. This descriptive comparative study comprises of 100 patients who are normotensive, diabetic and 80 normal healthy patients with age $>35$ years were included in the study with convenient consecutive sampling after proper written informed consent. The patients were taken from OPD and indoor wards of medicine department with type 2 diabetes mellitus with fasting glucose more than $126 \mathrm{mg} / \mathrm{dL}$ and/or 2-hr PP glucose more than $200 \mathrm{mg} / \mathrm{dL}$ were included in the study. Investigations like Fasting and Postprandial blood sugar levels, Serum creatinine, fasting lipid profile, HbA1c and ECG were carried out and Echocardiographic assessment was done by using Model HD7 XE Phillips 2D ECHO machine.

\section{Inclusion Criteria}

1. Patients with Diabetes mellitus who are Normotensive type 2 diabetic patients aged 35 - 65 yrs.

2. Patients with type 2 diabetes mellitus without any complications of diabetes.

\section{Exclusion Criteria}

a. Patients with Pre-existing ischaemic heart disease.

b. Thyroid Disease.

c. Renal Disease.

Patients taken in the study were treated as per standard treatment schedule except beta blockers, which was withheld one week before Echocardiography. Data were entered in MS Excel spread sheet and analysed with the help of SPSS version 16 software packages and Statistical analysis was done by using percentages, mean values, standard deviation, standard error, $x^{2}$ test (Chi-square test) (with Yates correction), t-test (unpaired). The level of significance used was 0.05 level for the corresponding degree of freedom to draw the inference. A p-value $<0.05$ was considered statistically significant and a p $>0.05$ was considered as not statistically significant with value $<0.001$ as highly significant.

\section{RESULTS}

All the patients were evaluated for cardiac functions by noninvasive cardiac diagnostic techniques. Nomograms of 80 age and sex matched normal subjects were taken for comparisonGroup 1 - Type 2 diabetes mellitus patients (Study group). Group 2 - Normal population (Control group).

Maximum number of patients were in the age group of $35-40$ and least number of patients were in the age group of $>60$ present in our study. $50.0 \%$ of the male and $45.0 \%$ of the female were present and male: female ratio was 1.22:1. Majority of patients $(76.0 \%)$ had duration of diabetes $>5$ years and only $24.0 \%$ had duration of diabetes $<5$ years and mean duration of diabetes in study group was 7.62 years $(25$ \pm 19.30 ). In study group, mean FBS was $183.7 \pm 15.0$ and PPBS was $252 \pm 25.67$ which were higher than control group. Hence, mean FBS and PPBS in study group was highly statistically significant $(p<0.001)$ as compared to control group (Table 1). Maximum number of patients, i.e. $50.0 \%$ were in the range of $\mathrm{HbA} 1 \mathrm{c}$ level from 7.1 to $8 \%$ and least number of the patients i.e. $12.0 \%$ were in the range of $>8.0 \%$. $16 \%$ (16) of the patients had decreased $\mathrm{EF}<50 \%$ out of 100 in the study group as compared to control group 2\% (80), which is statistically significant i.e. $\mathrm{p}<0.001$ (Table 2). EF $>50 \%$ were $84 \%$ present; in duration of diabetes mellitus from 5 to 15 years and patients with $\mathrm{EF}<50 \%$ were $16 \%$ present in duration of diabetes mellitus from 5 to 15 years. There is no positive correlation of $\mathrm{EF}$ with the duration of diabetes mellitus (Table 3). A/E ratio > 1 was present in $82 \%$ of the patient in study group indicating Diastolic Dysfunction and A/E ratio $<1$ in study group and control group were $18 \%$ and $100 \%$ respectively. Hence, $\mathrm{A} / \mathrm{E}$ ratio $>1$ were present only in study group, which was highly statistically significant (Table 4). Maximum number of patients with $\mathrm{A} / \mathrm{E}>1$, i.e. $82 \%$ were in the duration of diabetes mellitus from 5 to $>15$ yrs. and $\mathrm{A} / \mathrm{E}<1$ i.e. $18 \%$ were in duration of the diabetes mellitus from 5 to $>15$ yrs. Hence, there is no positive correlation of duration of diabetes mellitus with A/E ratio $>1$ (Table 5). In the present study, 70 patients had IVRT of $>100$. All these patients also had A/E ratio of $>1$. IVRT was within normal range in 20 patients and it was $<60 \mathrm{msec}$ in 10 patients who also had coexisting LV systolic dysfunction with ejection fraction of $<50 \%$.

\section{Mean Value}

\begin{tabular}{|c|c|c|c|c|}
\hline Sl. No. & Study Group & FBB & PPBS & P value \\
\hline 1 & Study Group & $183.7 \pm 15.0$ & $252 \pm 25.67$ & \multirow{2}{*}{ P $<0.001$} \\
\hline 2 & Control Group & $80.2 \pm 13.25$ & $112.4 \pm 16.20$ & \\
\hline \multicolumn{5}{|c|}{ Table 1. Table showing Blood Glucose Level } \\
\hline
\end{tabular}

\begin{tabular}{|c|c|c|c|c|c|}
\hline Sl. No. & Study Group & EF $>$ 50\% & EF $<$ 50\% & Total & P value \\
\cline { 1 - 4 } 1 & Study Group & $84(84 \%)$ & $16(16 \%)$ & 100 & P $<$ \\
\hline 2 & Control Group & $80(98 \%)$ & $80(2 \%)$ & 80 & 0.001 \\
\hline \multicolumn{7}{|c|}{ Table 2. Table showing Ejection Fraction } \\
\hline
\end{tabular}

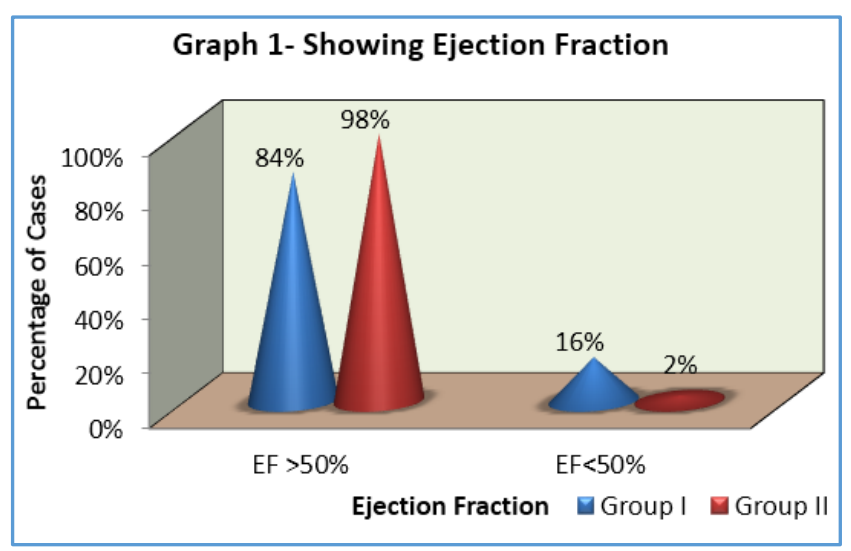

\begin{tabular}{|c|c|c|c|c|}
\hline Sl. No. & Duration & EF $>\mathbf{5 0 \%}$ & $\mathbf{E F}<\mathbf{5 0 \%}$ & Total \\
\hline 1 & $<5$ yrs. & $21(87.5 \%)$ & $03(12.5 \%)$ & 24 \\
\hline 2 & 5 to 10 yrs. & $43(82.69 \%)$ & $09(17.31 \%)$ & 52 \\
\hline 3 & 10 to 15 yrs. & $14(82.35 \%)$ & $03(17.65 \%)$ & 17 \\
\hline 4 & $>15$ yrs. & $06(85.71 \%)$ & $01(14.29 \%)$ & 07 \\
\hline \multicolumn{4}{|c|}{ Table 3. Table showing the Relation of Duration } \\
of DM with Ejection Fraction \\
\hline
\end{tabular}




\begin{tabular}{|c|c|c|c|c|c|}
\hline Sl. No. & Group & A/E $>1$ & A/E $<1$ & Total & P value \\
\cline { 1 - 5 } 1 & Study Group & $82(82 \%)$ & $18(18 \%)$ & 100 & P \\
\cline { 1 - 3 } & Control Group & 00 & $80(100 \%)$ & 80 & $<0.001$ \\
\hline Table 4. Table showing Ratio of A-Wave Velocity and E- \\
Wave Velocity \\
\hline
\end{tabular}

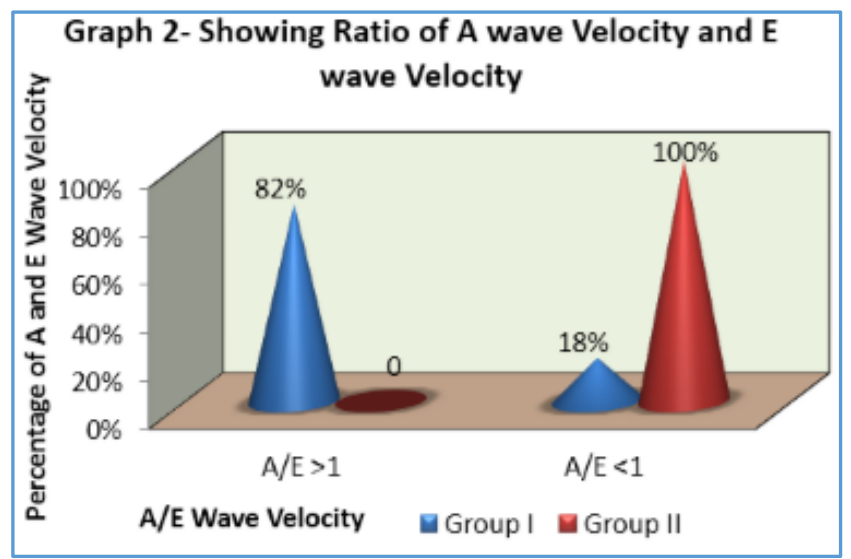

\begin{tabular}{|c|c|c|c|c|}
\hline Sl. No. & Duration & $\mathrm{A} / \mathrm{E}>\mathbf{1}$ & A $/ E<1$ & Total \\
\hline 1 & $<5$ yrs & $21(87.5 \%)$ & $3(12.5 \%)$ & 24 \\
\hline 2 & 5 to 10 yrs. & $42(80.76 \%)$ & $10(19.24 \%)$ & 52 \\
\hline 3 & 10 to 15 yrs. & $13(76.47 \%)$ & $4(23.53 \%)$ & 17 \\
\hline 4 & $>15$ yrs. & $06(85.71 \%)$ & 01(14.29\%) & 7 \\
\hline & & 82 & 18 & 100 \\
\hline
\end{tabular}

\section{DISCUSSION}

In our study, mean age of the present study (47) was comparable to that of Poirie et $\mathrm{al}^{1}$ (2003) (48 years), Khaliq et $\mathrm{al}^{2}$ (2001) (51 years) and Boyer et $\mathrm{al}^{3}$ (2004) (49.8 years). In the present study, $50.0 \%$ of the male and $45.0 \%$ of the female were present which is comparable to Patil et $\mathrm{al}^{4}$ (2007) studies 50 diabetic patients of which 28 (56\%) were male and 22 (44\%) were female. Poantă et $\mathrm{al}^{5}$ (2010) studies 62 diabetic patients, of which 32 (51.62\%) were male and 30 (48.38\%) were female. The present study has mean duration of the disease as 7.6 years, which is comparable to that of Poirie et $\mathrm{al}^{1}$ (2003) (4.8 years), Khaliq et $\mathrm{al}^{2}$ (2001) (4 years) and Boyer ${ }^{3}$ (2004) (5.8 years).

The FBS (183 $\mathrm{mg} \%$ ) and PPBS (252 mg\%) levels in the present study are significantly lower, which is comparable to study by Khaliq et $\mathrm{al}^{2}$ (2001) showed the mean FBS of $203 \pm$ 51 and mean PPBS of $261 \pm 56$. This may be because of factors like genetics and environmental factors, modes of management of diabetes and BMI.

In the present study, $16(16 \%)$ patients had significantly decreased ejection fraction of $<50 \%$. Whereas, Naik et al ${ }^{6}$ (2009) showed EF $<50 \%$ in $6 \%$ of diabetic patients and Khaliq et $\mathrm{al}^{2}$ (2001) had 18 (28\%) patients with ejection fraction $<50 \%$.

Velocities of mitral A-wave A/E ratio were significantly higher in the present study indicating left ventricular diastolic dysfunction. In the present study, 82 patients had A/E ratio of $>1$ constituting $82 \%$ of study group, which is comparable to that of Boyer et al and Valle et al which is $75 \%$ and $51 \%$ respectively. 18 patients had $\mathrm{A} / \mathrm{E}$ ratio $<1$. A/E $>1$ is very sensitive and specific indicator of $\mathrm{LV}$ diastolic dysfunction. In the present study, the late atrial filling wave (A) was significantly increased, probably due to elevated LV filling pressure secondary to impaired relaxation among diabetic individuals. The diastolic abnormalities in diabetic patients most likely to indicate reduced LV compliance secondary to small vessel disease, infiltrative myocardial process, metabolic derangement or a combination of the three.

Zarich et al ${ }^{7}$ (1988) and Papillolec et al ${ }^{8}$ (1989) reported that diabetics who had normal ejection fraction had evidence of diastolic dysfunction in the form of increased A/E ratio. They also found that LV fractional shortening was normal in majority of subjects who had increased A/E ratio among diabetics.

In the present study, there was no correlation of diastolic dysfunction with the duration of diabetes which is comparable to the study by Grandi et al ${ }^{9}$ (2006) who concluded that the severity of diabetes mellitus is more important than duration of diabetes mellitus for the development of diastolic dysfunction.

In the present study, the isovolumetric relaxation time (IVRT) showed mean and SD of $102 \pm 20.14$ as compared to IVRT mean of Poirie et $\mathrm{al}^{1}$ (2003) and Boyer et $\mathrm{al}^{3}$ (2004) showing $109.11 \mathrm{msec}$ and $79.14 \mathrm{msec}$ respectively, which is statistically significant. The prolongation of IVRT more than $100 \mathrm{msec}$ is a significant indicator of early LV diastolic dysfunction. In the present study, 70 patients had IVRT of > 100 . All these patients also had A/E ratio of $>1$. Hiramatsu 10 (1992) and Papillolec et al $^{8}$ (1989) showed in their studies that diabetic patients had greater isovolumetric relaxation time.

In the present study, echocardiographic evidence of LV diastolic dysfunction among asymptomatic type 2 diabetes mellitus patient was recognised in more than $50 \%$ of patients and systolic dysfunction was seen in only $16 \%$ of patients.

\section{CONCLUSION}

Cardiac dysfunction, predominantly involving LV diastolic function is commonly seen in asymptomatic normotensive Type 2 DM patients. Alteration of A/E ratio $>1$ is a sensitive and specific indicator of early diastolic dysfunction. There is a positive correlation of diastolic dysfunction with severity of diabetes mellitus, but not with the duration of diabetes mellitus. Hence, severity of diabetes mellitus is more important that duration of diabetes mellitus because patient with short duration of diabetes mellitus but with uncontrolled blood glucose level can lead to early diastolic dysfunction in diabetic patients. LV diastolic dysfunction in asymptomatic normotensive patients with type $2 \mathrm{DM}$ without evidence of coronary heart disease is significantly higher.

LV systolic dysfunction was seen in a small number of asymptomatic normotensive Type $2 \mathrm{DM}$, which may point towards prevalence of silent cardiac muscle disease in asymptomatic Type $2 \mathrm{DM}$.

Conventional echocardiography is a simple economical test for detecting LV dysfunction in normotensive, asymptomatic and type 2 diabetic patients, and should be applied to detect early Left ventricular dysfunction so that actively preventive and therapeutic treatment could be planned early to prevent long-term morbidity and mortality and LV functions may be preserved for long. 


\section{REFERENCES}

[1] Poirier P, Bogaty P, Philippon F, et al. Preclinical diabetic cardiomyopathy: relation of left ventricular dysfunction to cardiac autonomic neuropathy in men with uncomplicated well-controlled type 2 diabetes. Metabolism 2003;52(8):1056-61.

[2] Annonu AK, Fattah AA, Mokhtar MS, et al. Left ventricular systolic and diastolic functional abnormalities in asymptomatic patients with noninsulin-dependent diabetes mellitus. Journal of The American Society of Echocardiography 2001;14(9):885-91.

[3] Boyer JK, Thanigaraj S, Schechtman KB, et al. Prevalence of ventricular diastolic dysfunction in asymptomatic, normotensive patients with diabetes mellitus. The American Journal of Cardiology 2004;93(7):870-5.

[4] Patil VC, Patil HV, Shah KB, et al. Diastolic dysfunction in asymptomatic type 2 diabetes mellitus with normal systolic function. J Cardiovasc Dis Res 2011;2(4):21322.

[5] Poantă L, Fodor D, Albu A. Left ventricular function in patients with uncomplicated well-controlled diabetes mellitus. Med Ultrason 2010;12(3):184-7.
[6] Nakai H, Takeuchi M, Nishikage T, et al. Subclinical left ventricular dysfunction in asymptomatic diabetic patients assessed by two-dimensional speckle tracking echocardiography correlation with diabetic duration. Eur J Echocardiogr 2009;10(8):926-32.

[7] Zarich SW, Arbuckle BE, Cohen LR, et al. Diastolic abnormalities in young asymptomatic diabetic patients assessed by pulsed Doppler echocardiography. J Am Coll Cardiol 1988;12(1):11420.

[8] Papillae C, Dahan M, Paycha F, et al. Prevalence and significance of left ventricular filling abnormalities determined by Doppler echocardiography in type 1 (insulin dependent) diabetic patients. Am J Cardiol 1989;64(16):1010-6.

[9] Grandi AM, Piantanida E, Franzetti I, et al. Effect of glycemic control on left ventricular diastolic function in type 1 diabetes mellitus. Am J Cardiol 2006;97(1):71-6.

[10] Hiramatsu K, Ohara N, Shigematsu S, et al. Left ventricular filling abnormalities in non-insulindependent diabetes mellitus and improvement by a short-term glycemic control. Am J Cardiol 1992;70(13):1185-9. 